\title{
Research on the Factor Analysis and Logistic Regression with the Applications on the Listed Company Financial Modeling
}

\author{
Pengwen Xiao \\ Guangdong University of Science \& Technology, \\ Dongguan 523083,China
}

\begin{abstract}
In this paper, we conduct research on primary factor analysis and logistic regression with applications on the listed company financial modeling. In this paper, the brief introduction of the basic background of China's listed companies financial index research and the research process, on the basis of systematic analysis of the listed company financial index compiled by the theoretical and practical significance, the nature of the index, definition and its components, and the index compiled by the basic train of thought and the key problem. We believe that the formulation of China's listed company accounting information and financial index is the expansion of financial analysis, compared with the traditional accounting and financial information, open, repeatable collect data base and the editing and release of appropriate subject is financial index, two important problems in research and preparation. Our research combines the factor analysis and logistic regression to form the novel and revised form of financial modelling paradigm that is innovative.
\end{abstract}

Keywords- Factor Analysis, Logistic Regression, Listed Company, Financial Modeling, Application.

\section{Introduction}

In the fierce competition in contemporary market economy condition, the listed company is managed independently and self-financing economic entities, therefore, the pursuit of value maximization is the ultimate goal of modern enterprises. In practice listed companies tend to be most concerned about how to create profit and value, and ignore subsequent enterprise risk. However, under the condition of market economy, listed companies are facing growing uncertainty, risk and benefit are inseparable, if the focus on corporate performance or value, and ignore the enterprise risk, for all kinds of risks, not take appropriate measures to deal with in time, the enterprise may suffer from the losses, even so have failed. For different listed companies, facing the financial risk is different, and even from the financial statements is relatively similar risks, but also because of listed companies are at different stages of the development or different market conditions, with financial management methods must be used to deal with the occurrence of different risks, so as to effectively prevent, control and avoid the financial risk.

According to the literature review, the primary challenges for the listed company financial as daily management pattern could be general summarized as the follows. (1) Financial risk transfer strategy. Financial risk transfer refers to the enterprise through certain means the financial risk transferred to other units namely enterprise through certain means to transfer some or all of the financial risk to the other people to assume. (2) Financial risk diversification strategy. Don't put all your eggs in the one basket, a listed company according to the actual situation to adopt multiplex, multilateral investment, various financing way of dispersing the financial risk. For riskier investments, the listed company can through joint investment with other companies, so as to disperse investment risk. Diversification, for example, it is enterprise diversification through long practice. (3) Financial risk mitigation strategy. The risk aversion is refers to the enterprise, when choosing financial plans should be comprehensive evaluation of various financial plans risk may happen in the future, according to different situations, adopt different 
ways to circumvent, to eliminate the risk of a future bait in the bud [1-3].

Financial management pattern is through the general establishment of a set of the effective system arrangement to make the distribution of the various stakeholders to participate in enterprise financial gains, in order to realize the interests of property rights. To participate in the allocation of corporate financial control, to form a mechanism of checks and balances, protect their rights from infringement, so as to achieve the purpose of long-term cooperation financial management mode as the embodiment of the financial aspects of corporate governance, financial governance structure, financial governance mechanism, the interaction system of the financial management behavior three aspects. The financial governance structure refers to financial decision-making, financial affairs and financial supervision within the company the rational allocation of different management levels, including the arrangement of financial function and financial personnel so as to form the governance. In the following figure one, we demonstrate the general procedures of the listed company financial modeling.

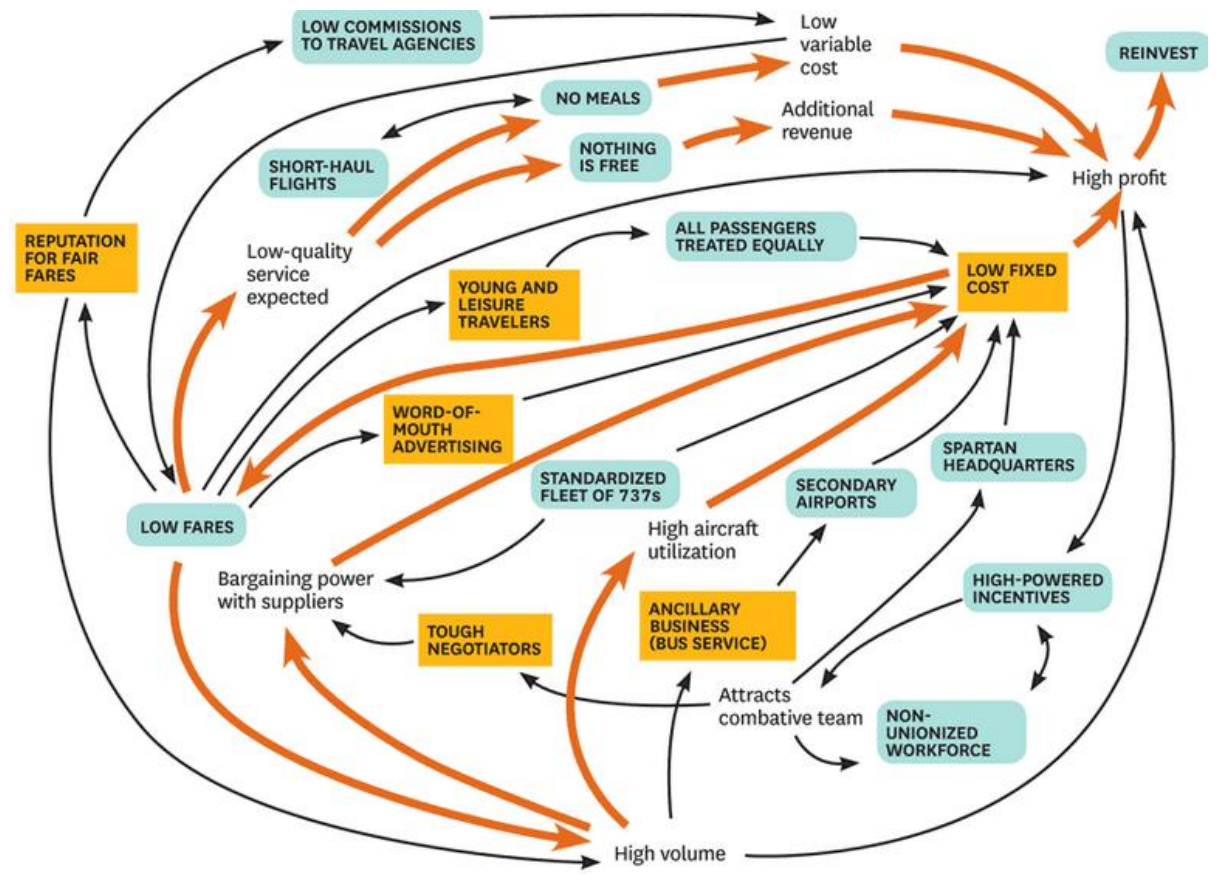

Figure 1. The General Procedures of the Listed Company Financial Modeling

In this paper, we conduct research on factor analysis and logistic regression with the applications on the listed company financial modeling. It is the core operation of the financial management financial governance structure is the carrier of financial governance mechanism, as well as the behavior of the financial management objective. Financial governance mechanism is the financial management of the internal control device, the financial activities within the basic territory of governance to conduct a comprehensive adjustment and the control. Financial management behavior is based on the financial governance structure, and under the guidance of financial governance mechanism, and correction of the financial governance body behavior constraints, and thus improving the efficiency of the financial governance. Financial governance structure, governance mechanism and the financial management behavior is closely related, interaction, forming different financial management mode [4-5]. 


\section{The Proposed Methodology}

The Factor Analysis Pattern. Enterprise financial diagnosis originated in the United States and with the development of science and technology and market competition, the survival and development of enterprises in order to have to focus on the financial problems of their own, in the case of itself is not solved, that had to turn to social management experts. Financial diagnosis as an important part of enterprise diagnosis is also an important link in enterprise financial management. Financial diagnosis is a kind of improving enterprise financial management advanced, scientific method, it overcomes the generalization of basic corporate financial analysis, formulation, such as weakness is the deepening of financial analysis and the development, and financial analysis is more scientific, comprehensive and practical. To carry out financial diagnosis is helpful to improve the enterprise financial management level and economic benefits. By financial diagnosis, managers can find the problems existing in the enterprise financial management that provide feasible suggestions for management decision.

This paper argues that can through the factor analysis model to establish comprehensive evaluation index and common factor analysis indicators for financial competitiveness evaluation and the specific financial competitive advantage, disadvantage of basic measurement. The method in constructing the comprehensive evaluation index weight is through the mathematics involved in the change, not the human, has the objectivity and scientific nature. At the same time, by setting the public factor index set too much can solve the traditional methods, the disadvantages of the correlation between each other, it can clearly reveal the influence of the main causes of the enterprise financial competitiveness, find the key problems affecting enterprise financial competitiveness, to promote the competitiveness of enterprise financial development is of great significance. To demonstrate the analysis mode, in the following formula, we define the principles [6].

$$
X=A F+a \varepsilon
$$

Factor analysis model is based on the correlation between variables, variables are grouped as high correlation between variables within the group, but the correlation is low, the different groups of the variables in each group represents a basic structure, the basic structure is called public factor. In this paper, using principal component analysis based on the principal component model to determine the factor that is demonstrated as the formula two.

$$
Z_{i j}=\left[x_{i j}-\bar{x}_{j}\right] / \mathrm{s}_{j}
$$

In practical analysis, in order to let the public factor variables as there is a clear understanding of the meaning of varimax rotation, tend to load matrix makes the highest load on each of the public factor variables with the number of minimum and the revised form is expressed as the formula 3 .

$$
Y=\frac{\lambda_{1}}{\sum \lambda_{i}} F_{1}+\cdots+\frac{\lambda_{m}}{\sum \lambda_{m}} F_{m}
$$

The Principles of the Logistic Regression. In many practical applications, the correct recognition and minority analogy to the properly identify the majority is more valuable. Traditional classification methods, such as decision tree, naive Bayesian and neural network, etc., usually assume that all the classes are balanced, blindly pursue the classification accuracy of the model, the model is likely to lead to ignore the minority class instance, and then put a few class instance is divided into most of the class. Logistic regression is a method of statistical analysis can be used for the dependent variable binary sexual discrimination while the class samples by calculation of the a posteriori probability, the interpretation of the discriminant result can give a probability sense. LR model used in simple, does not require the error tends to normal distribution, also does not require the independent variable is the normal distribution. This method has been widely used in the 
economic, social science and science research, and many the other fields. But the LR variables multicollinearity between the predictions is sensitive to disturbance. In statistics, logistic regression is typical probability statistical classification model, it through the linear function fitting logarithmic likelihood ratio, for two types of problems, can be expressed as the formula 4.

$$
\ln \left(\frac{p(y=1 \mid x)}{p(y=2 \mid x)}\right)=w^{T} x
$$

Goal is to make learning to model the probability of correct classification of each instance of the logarithm and maximize, without considering the instance is most class instance or a class instance and could be generally expressed as the formula 5 .

$$
L(w)=\sum_{j=1}^{2} \sum_{i=1}^{N j} \ln p\left(y=j \mid x_{i}^{(j)} ; w\right)+\Lambda
$$

\section{The Listed Company Financial} Management. Financial competitiveness, fundamentally that is a collection of unique knowledge and skills to the role of the enterprise are to use dynamic integration of resources, to provide with the firm's ability to adapt to changing environment. This special ability is from the basis of the enterprise begins to produce the power of winning the competition. Due to the knowledge of financial competitiveness, thus it more on the advantage of the enterprise performance for knowledge or accumulating power, thus make financial competitiveness is not only the root of the competitive advantage, but also the source of competitiveness [7-8].

From the current situation of the development of basic financial competitiveness theory, financial competitiveness theory system itself also has many needs to be perfect, financial competitive analysis and comprehensive evaluation is to guide sharp weapon of enterprise competition and development. Use of financial competitiveness evaluation index system to evaluate the financial competitiveness of the enterprise, promote enterprise developing its potential, improve the economic benefit to establish competitive strategy for enterprises to provide new direction for enterprises to improve management, strive for and maintain sustainable competitive advantage to provide new way of thinking and all the investors and businesses can choose investment through financial competitiveness evaluation result object optimization decision that could be reflected from the figure two.

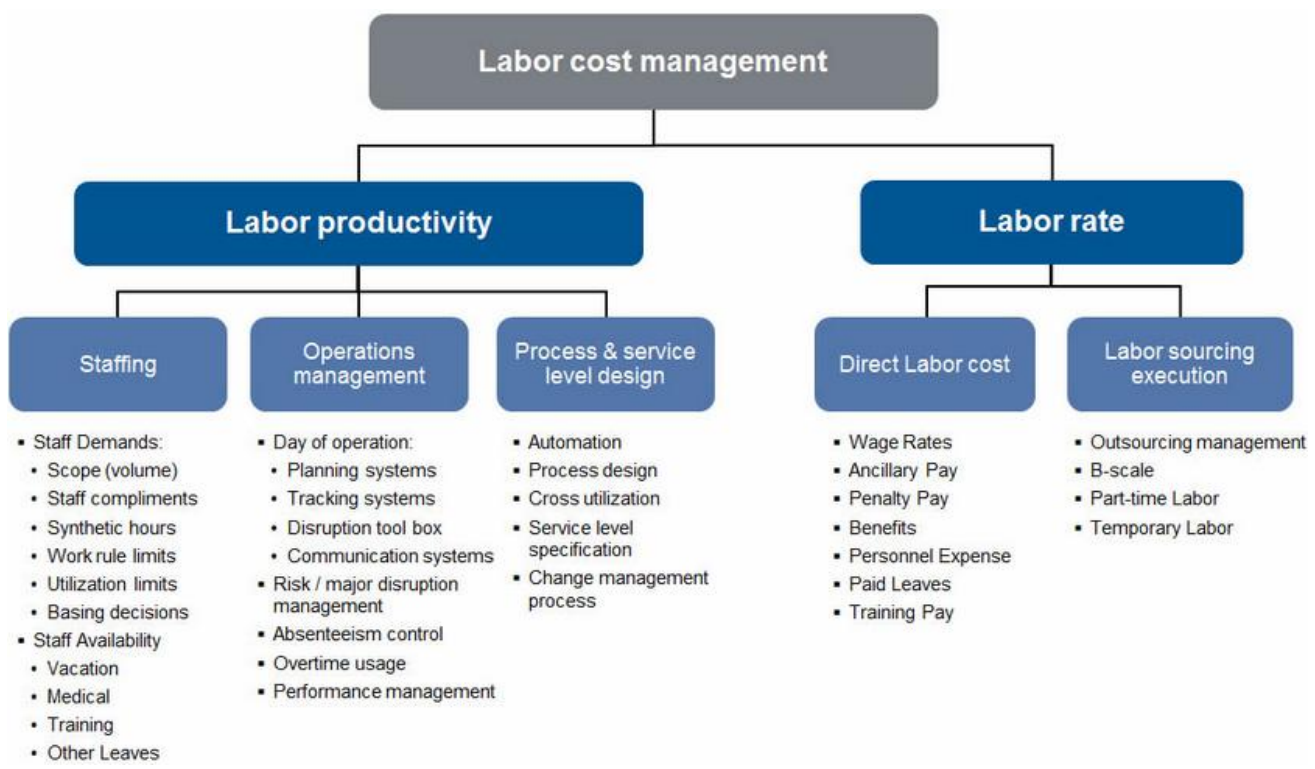

Figure 2. The Framework of the Listed Company Financial Management 


\section{The Novel Financial Modeling Paradigm.} In order to solve the estimation equation of linear and original data information is lost, we can introduction of principal component analysis in the Logistic analysis. It can be explained in model has many variables, at the same time realize the dimensionality of minimizing the loss of the information contained in the raw data, and replace the original data that between the main component of unrelated to each other.

Enterprise was in financial trouble in fact that is a gradual process, usually from financial normal development gradually to the financial crisis. Practice, most of the enterprise's financial woes are by worsening financial situation to normal gradually, eventually lead to financial distress or bankruptcy. Therefore, the enterprise financial difficulties not only have aura, and it is predictable and correctly predict corporate financial distress, to protect the interests of investors and creditors, for the operators to prevent financial crisis, for the government management department to monitor the quality of listed company and securities market risk which has the important practical significance [9].

Among the analysis of the model, we should take into consideration of the listed issues. (1) Management ability is the measure of enterprise financial resources use efficiency and appreciation ability that is the capital of velocity and assets increment rate and financial management of capital investment required and to recover as well as the distribution of the profits of link for basic scientific decision. (2) Growth ability is the ability to reflect the enterprise long-term development potential and trend, including profit growth ability and includes capital expansion ability. At present the main is to use growth index to reflect the growth ability of the enterprise. (3) Ability to pay is also called the debt paying ability, is refers to the enterprise in order to ensure the timely and full ability to repay its debts. How to determine the debt scale of enterprises, ensure enterprise's ability to pay, is one of the main content. (4) Profitability is refers to the enterprise due to sell products or invest benefit by the financial management object of capital movement of the incremental decision.

\section{Conclusion}

In this paper, we conduct research on factor analysis and logistic regression with the applications on the listed company financial modeling. Enterprise financial analysis is based on enterprise financial reports, and other relevant information as the main basis, evaluate the enterprise's financial position and operating results and analysis, reflect the enterprise in the process of operating the pros and cons and basic development trend, thus to improve the enterprise's financial management and optimizing economic decision provides important financial information and how to correctly understand the meaning of financial data, it is each investor must face with the problem. As a listed company, the enterprise's solvency and profitability is the core of the financial analysis indicators. In the future, we will combine more literature review to enhance the current model for optimization.

\section{References}

[1] Liu, Yang, Xungang Zheng, and Ling Tang. "Empirical Analysis of Enterprise Financial Sustainable Development Based on the Structural Equation. Examples of Automobile Listed Company in China." International Journal of Academic Research in Accounting, Finance and Management Sciences 3.2 (2013): 84-91.

[2] Scholtz, H. E., and A. Smit. "Executive remuneration and company performance for South African companies listed on the Alternative Exchange (AltX)." Southern African Business Review 16.1 (2013): 22-38.

[3] Abbaszadeh, Mohammad Reza, and Behzad Beigi. "The Effect of Corporate Governance 
Mechanisms on the Relationship between Investment Opportunities and Dividend Ratio of Listed Companies in Tehran Stock Exchange." Asian Journal of Research in Banking and Finance 4.1 (2014): 104.

[4] Qiu-san, Z. H. A. N. G., et al. "Research on the Financial Fraud Identification of the Listed Companies Based on Data Mining Techniques." Science Technology and Industry 11 (2014): 015.

[5] Binh, Ta Quang. "Voluntary disclosure information in the annual reports of non-financial listed companies: the case of Vietnam." Journal of Applied Economics and Business Research 2.2 (2012).

[6] Weng, Chai-fang. "Determinants of Stock Price Crash Risk in Taiwanese Listed Company: The Role of Corporate
Governance and Analyst

Recommendations." (2013).

[7] Zeng, Zhi-jian, Wei-yi Yang, and Chang-qing Luo. "A Study on the Impact of Cash Dividend Distribution on Earnings Persistence of Listed Company." The 19th International Conference on Industrial Engineering and Engineering Management. Springer Berlin Heidelberg, 2013.

[8] LI, Hai-hai, and Bo-bing DENG. "Monetary Policy Effect on the Capital Structure of Listed Companies: The Study Based on Industry Comparison." Journal of Central University of Finance \& Economics 11 (2014): 007.

[9] Iyoha, F. O. "Company attributes and the timeliness of financial reporting in Nigeria." Business Intelligence Journal 5.1 (2012): 41-49. 